\title{
CORRESPONDENCE
}

\section{CORNEAL ULCERATION WITH PS. PYOCYANEA}

\section{To the Editorial Committee of the British Journal OF OphThalmology}

Dear Sirs-Two recent articles by Klein and Millwood $(1952,1953)$ have prompted me to make a few comments on some eight cases of corneal ulceration with the $P s$. pyocyanea which I have seen since an article by Bignell appeared in 1951.

Of the eight cases, six had a simple corneal foreign body removed, and in these the cornea became infiltrated round the former site of the foreign body within 48 hours of its removal, and a typical pyocyaneus ulceration developed. One of the other two cases developed spontaneously in a previously healthy eye and the other in a patient in extremis (following the resection of a malignant caecum). In all cases the fully developed lesion was characteristic. The ulcerated area appeared dead white (slightly nodular) and covered at least one-half of the cornea. In most cases the ulcer had an overhanging epithelial edge $(2-3 \mathrm{~mm}$. in width) around one-half to one-third of its circumference. Outside this again was an area of infiltration. There was marked pain and some muco-purulent discharge. An hypopyon was noted in five cases and posterior synechiae were present in one.

Terramycin, polymixin, streptomycin, sulpha drugs, and aureomycin was tried systemically and locally. The only really effective treatment appeared to be daily subconjunctival injections of $0.5 \mathrm{~g}$. streptomycin (Bignell). This was dissolved in $5 \mathrm{mim}$. mydricaine (in $10 \mathrm{mim}$. sterile water). The injections resulted in severe pain and marked conjunctival reaction. In some cases the conjunctiva even sloughed over the site of the injections.

The healing of the ulcers was a slow process extending over many weeks and in each case resulted in a dense scar involving in the full thickness of the cornea. Vascularization occurred in most cases. The results (on an average 2 to 3 months later) were as follows:

Number of
$\mid 3$
2
1
1
1

$$
\begin{gathered}
\text { Resultant Visual Acuity } \\
6 / 18 \\
6 / 24 \\
6 / 36 \\
\text { Hand movements } \\
\text { Eye ruptured-patient died }
\end{gathered}
$$

In the last case mentioned the eye ruptured $72 \mathrm{hrs}$ after the onset of the ulcer, the lens being extruded. The patient died some 48 hrs later (malignant caecum-postoperative).

Seven of the above were seen while I was a senior house surgeon at the Western Ophthalmic Hospital, London, and the eighth case was seen in New South Wales, Australia.

Yours faithfully,

N. KerKenezov.

Lismore Base Hospital,

New South Wales, Australia. March 25, 1953.

\section{REFERENCES}

Bignell, J. L. (1:51). British Journal of Ophthalmology, 35, 419.

KLEIN, M., and MILlwood, E. G. (1952). Ibid., 36, 679.

(1953). Ibid., 37, 30. 